\title{
PALABRAS DEL GLARP EN LA CELEBRACION DE LOS 25 AÑOS DE LA ASOCIACION COLOMBIANA DE TERAPEUTAS OCUPACIONALES
}

Para el GRUPO LATINOAMERICANO DE REHABILITACIÓN PRO. FESIONAL -en siglas GLARP-, participar en esta reunión es un honor y se constituye en una magnífica oportunidad de compartir junto con Ustedes-Directivas, afiliadas y afiliados, amigas y amigos, esta celebración que nos llena de la alegría que sentimos por la permanencia durante 25 años de su Asociación. Hacemos bien al suponer que este lapso de tiempo es el reflejo de un árduo trabajo en búsqueda de su identidad común, sustentabilidad y sostenibilidad.

La historia del GLARP en sus veinte años de existencia, ha estado siempre muy ligada al desarrollo de la Terapia Ocupacional y nuestra organización ha contado en forma permanente con el valioso concurso, colaboración y participación activa de destacadas personas de esta comunidad profesional. Esta situación nos llama a hacer un franco reconocimiento de la potencialidad que como disciplina del conocimiento y como ciencia que profundiza en la ocupación humana, tiene ella para dinamizar procesos humanosociales que procuran el bienestar de la persona y de la comunidad en su realización como individuos y organizaciones productivas, capaces objetivamente de contribuir a la transformación de una realidad que a todas luces, es injusta e inequitativa con una porción muy grande de la población de nuestro país.

Como ustedes saben el GLARP es un organismo privado de cooperación, Sin Animo de Lucro, integrado en forma de Red Interinstitucional, cuyo ámbito de acción cobija a 16 países de América Latina con 132 Instituciones afiliadas cuya esfera de gestión se ubica en la Rehabilitación Profesional.

Co-gestiona proyectos orientados a facilitar el mejoramiento de las condiciones objetivas de la calidad de vida de las personas con discapacidad y 
fortalece la capacidad operativa de las organizaciones de y para esta comunidad, contribuyendo al logro de prestación de servicios normalizados, oportunos y flexibles a sus necesidades e intereses.

Por nuestra razón de ser y de concebir nuestro quehacer, consideramos que la rehabilitación integral debe buscar la integración de la persona con discapacidad a la sociedad, a través del ejercicio de roles que le son propios y que desea desempeñar.

Su integralidad no se da con base en la secuencialización de etapas - consideración que ha sido superada tanto en la teoría como en la práctica-, sino en función del resultado a alcanzar.

Y es aquí donde encontramos una identificación con los fundamentos de la Terapia Ocupacional, puesto que ella -tanto como nosotros-está comprometida con el logro de la aspiración humana de una verdadera, objetiva, demostrable y medible, integración social y laboral de todas y todos los seres humanos, en un marco caracterizado definitivamente por la equiparación de oportunidades y la normalización.

Es fascinante observar cómo la Terapia Ocupacional establece relaciones entre la actividad de una persona -sin diferenciación en sus características, habilidades y destrezas-con la concepción de un desarrollo integral y en forma consecuente con el ejercicio pleno y el mantenimiento de roles en el grupo social al que pertenece, en un proceso de promoción de valores y metas individuales y comunitarios. Esto, a primera vista, le da una perspectiva totalizante según la cual, no solamente se debe limitar a una visual funcional sino que se extiende también a esferas que exploran el desarrollo educativo, económico, social, cultural y organizacional de los seres humanos como sistemas transformadores de una realidad que se expresa tanto en la cotidianidad de la vida como en lo que se ha dado por llamar el Desarrollo Humano Sostenible.

La situación de la Colombia de hoy, en donde a nivel urbano casi el $50 \%$ y a nivel rural un escandaloso $75 \%$ de la población se encuentra por debajo de la línea de la pobreza, nos llama a una profunda reflexión sobre el aporte que la Terapia Ocupacional debe cumplir en la transformación y en el desarrollo social. 
No en vano su ejercicio profesional se ha extendido a diversas facetas de trabajo: la academia, el sector gubernamental, la empresa privada, instituciones de salud y de trabajo, la gerencia de servicios. Esto es un indicador claro y preciso no sólo de la ampliación de su esfera de acción sino también de la responsabilidad que les compete en la generación de formas alternativas de vinculación con el medio para las personas que requieren de sus acciones de intervención, en un modelo de desarrollo socio-económico que parece -aunque no se le reconozca-haber demostrado históricamente su ineficacia.

El mundo de hoy se caracteriza por estar inmerso en la era del conocimiento, como fruto de la interrelación del saber, las telecomunicaciones y la informática.

Estas condiciones actuales, exigen el aporte dinámico de todas las profesiones, entre ellas la Terapia Ocupacional, para impulsar la productividad de nuestros recursos, -el humano, el principal- desarrollar el conocimiento y el saber local con proyección global, continuar con un sano proceso de evolución de los sistemas sociales de salud, de educación y de trabajo hacia la plena accesibilidad y fomentar la autogestión y el desarrollo comunitario.

En esta tarea se encuentra el GLARP conjuntamente con otras organizaciones entre éstas Ustedes; trabajando día a día, sin perder la focalización sobre el ser humano que con o sin discapacidad aparente, con habilidades y necesidades especiales y con sus organizaciones, busca la promoción a través de su propio esfuerzo, siendo éste responsable de su propio desarrollo, reivindicando así sus derechos pero también sus deberes.

No pretendemos tener todas las respuestas -eso nos garantiza una mente abierta a propuestas novedosas y un espíritu permanente de trabajo y compromiso con la misión que desarrollamos; inclusive tampoco conocemos todas las preguntas-eso promueve en nosotros una actitud institucional de investigación y de reflexión sobre la rehabilitación profesional, el entorno y la ecología humana y social. Por estas razones las y los invitamos a todas $y$ todos ustedes, Terapeutas Ocupacionales, a continuar trabajando juntos 
por la construcción de un entorno que considere a la actividad humana como el verdadero motor de desarrollo de nuestro país.

Doctor

JULIAN OSPINA LEAL

Coordinador Area Proyectos 